other than to go about my work and wait for news.

So when, later that morning, I met Mr. Hussein and saw his hands, smooth and thick, just like my father's I opted to speak in my father's mother tongue. In a moment of personal vulnerability I found the courage to speak my rusty Punjabi despite Mr. Hussein's good English.

Later, after rounds, my father called to tell me that his tests had been normal and he would be going home the next day. After experiencing huge relief, my mind turned to $\mathrm{Mr}$. Hussein and our conversation at the end of our meeting, in particular my mention of 1947.

The "partition" of India in 1947 resulted in the birth of 2 nations: the Republic of India and Pakistan. The idea was that millions of Indian Muslims would move to Pakistan and millions of non-Muslims (e.g. Hindus, Sikhs and Jains) would move from Pakistan to India. The 2 new nations were grossly unprepared for what would become the largest population movement in recorded history. The result was horrific intercommunal violence, which left half a million people dead. The trauma of 1947 still kindles tensions between these 2 neighbours today.

With my own hospitalized father on my mind, I had spoken Punjabi without thinking through the cascade of questions it would trigger. Punjabi is a dialect specific to Northern India and parts of Pakistan, so speaking it to a Pakistani patient inevitably would invite questions about where I was from. Like Mr. Hussein, my last name too hints to my religious identity; hearing the spelling informed him that I was not a Muslim. Disclosing my father's birthplace revealed that the partition had affected my family's life directly. History placed us on opposite sides of this smoldering conflict.

Had I burdened Mr. Hussein by disclosing too much information about myself and given him reason to not trust me? When people are depressed they can find it hard to accept help and the stigma of mental illness itself can make them find reasons to avoid treatment. The self-disclosures could have been avoided if we had spoken English.

The following day, on rounds, I reiterated to Mr. Hussein my treatment recommendations. He appeared engaged, but I was sure he would abandon his treatment.

I was wrong.

Over the past year, he has come to see me every month for follow-up, despite the fact that my clinic is far from his home and has stairs unfriendly for an elderly man who walks with a cane. It seems that my self-disclosures, though clumsy, may have also given rise to a transparency that, ultimately, worked in our favour as doctor and patient.

$\mathrm{He}$ is doing quite well. And we always speak in Punjabi.

\section{Shaili Jain MD}

Psychiatrist

Aurora Psychiatric Hospital

Milwaukee, USA

Dr. Jain thanks Ann Tennier for her assistance in the preparation of this manuscript.

\title{
More book reviews at cmaj.ca
}

Is narrative medicine for everyone?: Although the concepts and practice of narrative medicine come of age in the expertly written book, Narrative in Health Care (Radcliffe Publishing; 2008), the underlying philosophy isn't really anything new and the practice may not be for everyone. Shane Neilson MD, Guelph, Ont.

A life in letters: Sir Andrew Macphail (1864-1938), the founding editor of CMAJ and an internationally renowned essayist on political, social and intellectual themes, is the fascinating of subject of this new biography: Sir Andrew Macphail: The Life and Legacy of a Canadian Man of Letters (McGillQueen's University Press; 2008). - Charles G. Roland MD, Burlington, Ont.

Breast cancer blog: Laurie Kingston provides intimate glimpses into the day-to-day reality of living with breast cancer in Not Done Yet: Living Through Breast Cancer (Women's Press; 2009). For the busy practitioner, this book gives meaning to the stark exterior facts of the disease.Sharon Batt MA, Halifax, NS

The cisapride tragedy: Terence Young's 15-yearold daughter Vanessa was taking cisapirde for "mild bulimia" when she died in 2000. Death by Prescription: A Father Takes on His Daughter's Killer - the Multi-Billion-Dollar Pharmaceutical Industry (Key Porter Books; 2009) is a

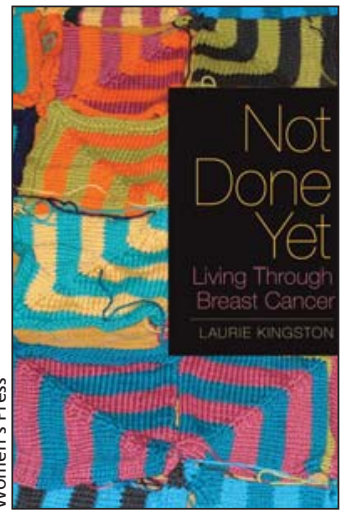
powerful recounting of Young's journey to find out why his daughter died. - Thomas L. Perry MD, Vancouver, BC

DOI:10.1503/cmaj.091367 